\title{
Histological changes of testes in growth hormone transgenic mice with high plasma level of GH and insulin-like growth factor-1
}

\author{
Katarzyna Piotrowska ${ }^{1}$, Sylwia Sluczanowska-Glabowska', Magda Kucia ${ }^{2}$, \\ Andrzej Bartke ${ }^{3}$, Maria Laszczynska ${ }^{4}$, Mariusz Z. Ratajczak ${ }^{2}$
}

${ }^{1}$ Department of Physiology, Pomeranian Medical University, Szczecin, Poland

${ }^{2}$ Stem Cell Institute at James Graham Brown Cancer Center, University of Louisville, USA

${ }^{3}$ Geriatrics Research, Departments of Internal Medicine and Physiology, Southern Illinois University School of Medicine, Springfield, IL, USA

${ }^{4}$ Department of Histology and Developmental Biology, Pomeranian Medical University, Szczecin, Poland

\begin{abstract}
Introduction. Overexpression of growth hormone (GH) leads to increase in insulin-like growth factor-1 (IGF-1) plasma level, stimulation of growth and increase in body size, organomegaly and reduced body fat. The action of GH affects all the organs and transgenic mice that overexpress bovine GH (bGH mice) serve as convenient model to study somatotropic axis. Male mice overexpressing GH are fertile, however, they show reduced overall lifespan as well as reproductive life span. The aim of the study was to evaluate the morphology and expression of androgen receptor (AR) and luteinizing hormone receptor (LHR) of bGH mice testes.

Material and methods. The experiment was performed on 6 and 12 month-old bGH male mice and 6 and 12 month-old wild type (WT) littermates (8 animals in each group). The morphology of testes was evaluated on deparaffinized sections stained by the periodic acid-Schiff (PAS) method. Expression of AR and LHR was investigated by immunohistochemistry and diameters of seminiferous tubules (ST) were measured on round cross sections of ST.

Results. We noted larger testes in 6-month bGH mice as compared to normal WT littermates. The morphological observations revealed essentially normal structure of Leydig cells, seminiferous epithelium and other morphological structures. However, some changes like tubules containing only Sertoli cells, tubules with arrested spermatogenesis or vacuoles in seminiferous epithelium could be attributed to the overexpression of GH. In contrast to WT mice, 12 month-old bGH mice displayed first symptoms of testicular aging. The immunoexpression of AR and LHR was decreased in 12 month-old bGH males as compared to 12 month-old WT mice and younger animals.

Conclusion. Chronic exposure to elevated GH level accelerates testicular aging and thus potentially may change response of Leydig cells to LH and Sertoli and germ cells to testosterone. (Folia Histochemica et Cytobiologica 2015, Vol. 53, No. 3, 249-258)
\end{abstract}

Key words: GH transgenic mice; testis histology; androgen receptor; LHR; IHC

Correspondence address: K. Piotrowska, Ph.D.

Department of Physiology

Pomeranian Medical University

Al. Powstancow Wlkp. 72, 70-111 Szczecin

e-mail: piot.kata@gmail.com 


\section{Introduction}

Growth hormone $(\mathrm{GH})$ exerts direct and indirect effects in almost every organ of the body, including the reproductive system [1-5]. Studies on various mutants of the somatotropic axis showed that decreased action of GH can lead to delayed sexual maturation, malfunction of gonads in both sexes and a decrease in fertility [3, 6-8]. On the other hand, overexpression of $\mathrm{GH}$ (bovine, human) in mice also leads to functional changes of the reproductive system $[9,10]$.

Growth hormone plays an important role in testicular growth and development including spermatogenesis, steroidogenesis and sperm motility [11]. $\mathrm{GH}$ is also responsible for development, maturation and proper function of Leydig cells [12]. Moreover, $\mathrm{GH}$ indirectly influences gonadal cells by increasing levels of insulin-like growth factor 1 (IGF-1) [13]. The presence of receptors for GH and IGF-1 has been demonstrated in rat testes [14].

Transgenic mice (males and females) overexpressing human GH placental variant (hGH-vTg) had reduced fertility, while males from several lines of bovine GH transgenic (bGHTg) mice have been reported to have normal fertility [9]. The reproductive function of $\mathrm{GH}$-overexpressing male mice including GH-vTg and bGHTg males, has been analyzed by comparing weight of sex organs, daily sperm production per testis and number of epididymal spermatozoa (with epididymal transition time) [9]. Breeding performance of hGH males was reduced as assessed by the percentage of pregnant females, although the testes and daily sperm production per testis were even greater than in their normal littermates [9]. It was concluded, that the lower fertility of hGH transgenic males is due to lactogenic effect of human GH in mice. In the same experiment, bGHTg male mice showed no changes in their breeding performance, except for the reduction in number of females that become pregnant after 1 week of exposure to bGHTg males and reduction of the reproductive life span in these animals. This was related to the fact that bovine GH is purely somatotropic - acts only on GH receptor and does not react with prolactin (PRL) receptor, as human GH in mutant mice [9]. The morphology of testes has not been examined in these studies.

bGH mice have a significantly shorter life span than wild type mice [9]. Our recent findings indicate that it may be partly due to accelerated aging of main body organs, as evidenced by pathological changes in several organs such as liver and kidneys [15].

The aim of the present study was to examine morphological changes in seminiferous tubules and Leydig cells in testes from 6- and 12-month-oldbGH and WT mice. Morphological changes of testes were not previously studied in this strain of mice.

\section{Material and methods}

Animals. This study was performed in accordance with the guidelines of the Animal Care and Use Committee of the Southern Illinois University, the Laboratory Animal Care Committee of the University of Louisville School of Medicine, and the Guide for the Care and Use of Laboratory Animals (Department of Health and Human Services, publication No. NIH 86-23).

The experiments were performed on adult 6- $(n=8)$ and 12-month-old bGH mice $(\mathrm{n}=8)$, and 6- and 12-month-old normal sublinings of transgenic mice, hereafter referred as wild type (WT) mice as control animals $(n=8$ in each group). Mice were housed in a room with a photoperiod of $12 \mathrm{~h}$ light and $12 \mathrm{~h}$ darkness and a temperature of $20^{\circ} \mathrm{C}$ and were given free access to standard rodent chow and tap water until the animals were sacrificed and the tissues collected.

Male phosphoenolpyruvate carboxykinase (PEPCK)-bGHTg male mice and their normal WT male siblings were originally produced by microinjecting the bGH structural gene fused with the promoter of the rat PEPCK gene into the pronuclei of fertilized mouse eggs [16]. The hemizygous $\mathrm{Tg}$ mice used in this study were produced by mating GH-Tg males with normal C57BL/6 × C3H F1 hybrid females.

Morphological studies. Testes were fixed in Bouin's fixative for 24 hours and, after dehydration, embedded in paraffin blocks. During slicing on microtome, 3 slices of each block were trimmed (10 $\mu \mathrm{m}$ thick) and further sections $(3 \mu \mathrm{m}$ thick) were collected on histological slides.

Deparaffinized sections of testes were hydrated and stained using the PAS (periodic acid-Schiff) method (BioOptica, Milano, Italy). After staining, sections were dehydrated and immersed in a droplet of mounting medium (Sigma-Aldrich, St. Louis, MO, USA). Images were collected with an Olympus IX81 inverted microscope (Olympus, Tokyo, Japan), with objectives' magnifications $\times 20, \times 40$ and $\times 60$ (oil immersion) with color camera and with CellSens image processing software (Olympus).

Immunolocalization of AR and LHR. Deparaffinized sections of testes ( $3 \mu \mathrm{m}$ thick) were hydrated and heat epitope retrieval was performed in microwave oven in retrieval solution buffer $\mathrm{pH}=6$ (Dako, Glostrup, Dennmark). After cooling to room temperature (RT) the slides were incubated with $0.3 \%$ solution of $\mathrm{H}_{2} \mathrm{O}_{2}$, washed twice with phosphate-buffered saline (PBS) and further incubated with $2.5 \%$ horse serum. After washing in PBS slides were incubated with primary antibody: rabbit anti-mouse AR (Thermo Scientific, Waltham, MA, USA) and rabbit an- 
ti-mouse LHR (Santa Cruz Biotech., Dallas, TX, USA) for $1 \mathrm{~h}$ in RT. After washing in PBS immunoreaction was visualized with ImmPRESS Universal Reagent and Vector NovaRED Substrate kit (with Nova Red dye) for peroxidase according to manufacturer's protocol (Vector Laboratories Inc., Burlingame, CA, USA). As a negative control, the primary antibody was replaced with PBS. Positive staining was defined by visual identification of a yellow/brown pigmentation in the light microscope. Intensity of immunoexpression was scored as negative $(-)$, weakly positive $(+)$, moderately positive $(++)$, and strongly positive $(+++)$. Images were collected with an Olympus IX81 inverted microscope (Olympus) with color camera and with CellSens image processing software (Olympus).

Measurements of diameters of seminiferous tubules. In cross sections of the testes diameter of the seminiferous tubules was measured on the microphotographs. Only round tubules were chosen for this measurement according to the protocol developed by Neves et al. [17]. Briefly, we measured diameter of tubules at the total magnification of $\times 400$ using ocular micrometer calibrated with a stage micrometer. Over 30 round or almost round tubules, were measured in 2 sections from each testis of each mouse.

Statistical analysis. The measurements of diameters of seminiferous tubules are presented as the mean \pm SD and median value. Student $t$-tests were done using the program STATISTICA for Windows (StatSoft Inc., Tulsa, OK, USA). The significance level considered was $p<0.001$.

\section{Results}

\section{Animals' body weight}

Average body weight of 6-month-old mice overexpressing bovine $\mathrm{GH}$ was greater compared to 6-month-old WT mice $(59.9 \pm 1.4 \mathrm{~g} v$ s. $37.6 \pm 4.4 \mathrm{~g}$, $\mathrm{n}=8$ per group), as well as in 12-month-old bGH mice compared to 12 -month-old WT mice $(60.21 \pm 7.05 \mathrm{~g}$ vs. $38.78 \pm 4.34 \mathrm{~g}, \mathrm{n}=8$ per group).

\section{Morphology of testes of 6-month-old mice overexpressing bovine $\mathrm{GH}$}

The testes of 6-month-oldmice overexpressing bovine GH were bigger than those of WT mice $(279 \pm 10 \mathrm{mg}$ vs. $218 \pm 10 \mathrm{mg} ; \mathrm{n}=8$ per group,) and no significant differences were noted between the testes from the same animal. At the microscopic level cellular hypertrophy and hyperplasia were evident (Figure 1B, D, F) as compared to testes of 6-month-old WT littermates (Figure $1 \mathrm{~A}, \mathrm{C}, \mathrm{E})$. In all cross sections seminiferous tubules with all stages of seminiferous epithelial cycle (I-XII) were present. Mitotic figures in the population of germ cells were observed. We also noted normal morphology of all generations of cells in a given stage in the seminiferous epithelial cycle in the majority of seminiferous tubules in both bGH and WT littermates (Figure 1). There were only a few cross sections with altered epithelium. In some of these tubules, we found Sertoli cells (Sc) only (Figure 1B, D), and in others there were missing generations of cells in a given stage of the seminiferous epithelial cycle and large vacuoles on the basis of the seminiferous epithelium (Figure 1A, D). Leydig cells with pale round nuclei and abundant spongy-like cytoplasm with lipid droplets in both groups of animals at 6 months of age were observed. There were only single cells presenting lipofuscin granules in the interstitial tissue of 6 months old bGH mice (Figure 1F).

\section{Morphology of testes of 12-month-old bGH mice}

The testes of 12-month-old mice overexpressing bovine $\mathrm{GH}$ (Figure 2B, D, F) were bigger compared to their normal WT littermates $(281 \pm 10 \mathrm{mg}$ vs. 220.18 $\pm 10 \mathrm{mg} ; \mathrm{n}=8$ per group). At the microscopic level there were signs of cellular hypertrophy and hyperplasia. We noted normal morphology of seminiferous epithelium with all generations of cells characteristic for the given stages of the seminiferous epithelial cycle. Few tubules displayed Sertoli cells and spermatozoa without other generations of germ cells (Figure 2A insert). Nevertheless, the number of cross sections with morphological abnormalities (like tubules containing only Sertoli cells and tubules with missing generations of cells of epithelial cycle) was higher than in mice at 6 months of age (data not shown). Additionally, in some cross sections of tubules, we observed vacuoles at the base of seminiferous epithelium (Figure 2B). Testes of 12-month-old bGH mice contained some tubules with missing generations of germinal cells (Figure 2D) and premature sloughed germinal cells (Figure 2D insert). In both groups of 12-month-old animals we noted adult Leydig cells with round, pale nuclei and well developed cytoplasm with lipid droplets. There was an increased number of lipofuscin-storing cells in the testicular interstitium of 12-month-old bGH mice as compared to their WT littermates and 6-month-old bGH mice (Figure 2E, F).

\section{Immunolocalization of $A R$ and $L H R$}

\section{Androgen receptor}

Positive reaction for AR was found in Sertoli cells, Leydig cells, peritubular myoid cells and also in spermatogonia and spermatocytes (Figure 3, Table 1). In 6-month-old WT animals the reaction for AR was moderately intense in Leydig cells' nuclei and cyto- 


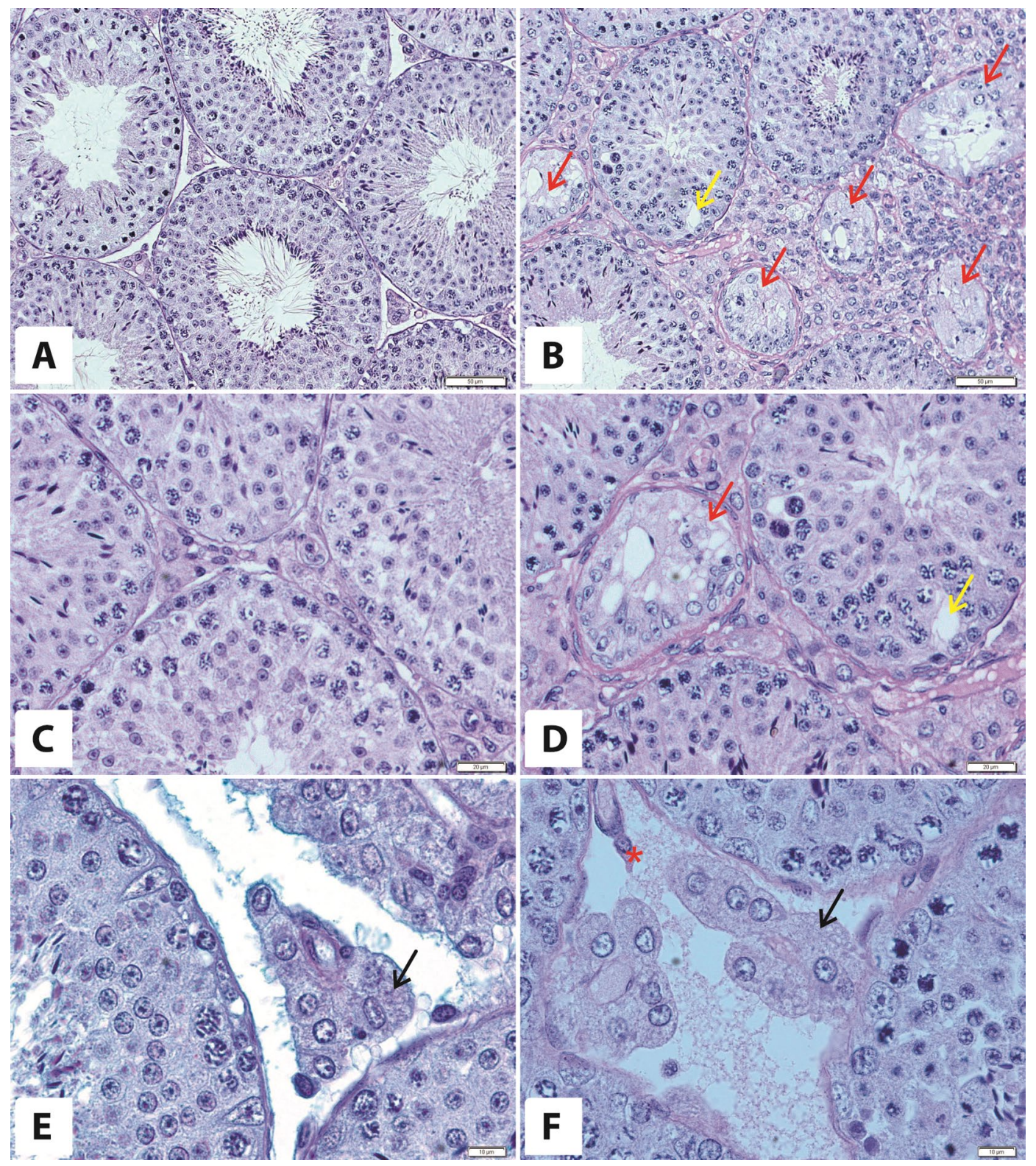

Figure 1. Morphology of a testis of 6-month-old WT (A, C, E) and bGH mice (B, D, F). Red arrows — tubules with only Sertoli cells, yellow arrow - vacuole, black arrows - Leydig cells, asterisk — lipofuscin-storing cell. PAS staining. Magnifications: $\times 20(A, B), \times 40(C, D), \times 60(E, F)$. Only representative microphotographs are presented

plasm and moderately positive in nuclei and cytoplasm of Sertoli cells, and weakly positive in peritubular myoid cells (Figure 3A, Table 1). Strong positive reaction was also observed in spermatids. In 6-month-old bGH mice, moderate immunoreactivity for AR was found in Leydig cells' nuclei and cytoplasm, nuclei and cytoplasm of Sertoli cells, spermatids and a weak AR immunoreactivity in peritubular myoid cells (Figure 3B, Table 1).

In 12-month-old WT animals, the AR immunoreactivity was strong in Leydig cells' cytoplasm, moderate in Leydig cells nuclei and weakly positive in nuclei and cytoplasm of Sertoli cells, as well as in peritubular myoid cells (Figure 3C, Table 1). The weak positive reaction was also observed in spermatids. In 12-months-old bGH mice moderate immunoreactivity for AR was found in Leydig cells' nuclei and cytoplasm, nuclei and cytoplasm of Sertoli cells, peritubular myoid cells and spermatids (Figure 3D, Table 1).

\section{Luteinizing hormone receptor}

Immunoreactivity for LHR was found in Leydig cells in all experimental groups (Figure 3E-H, Table 1). Strong positive reaction was observed in membranes and cytoplasm of Leydig cells in 6-month-ldbGH and WT animals. 


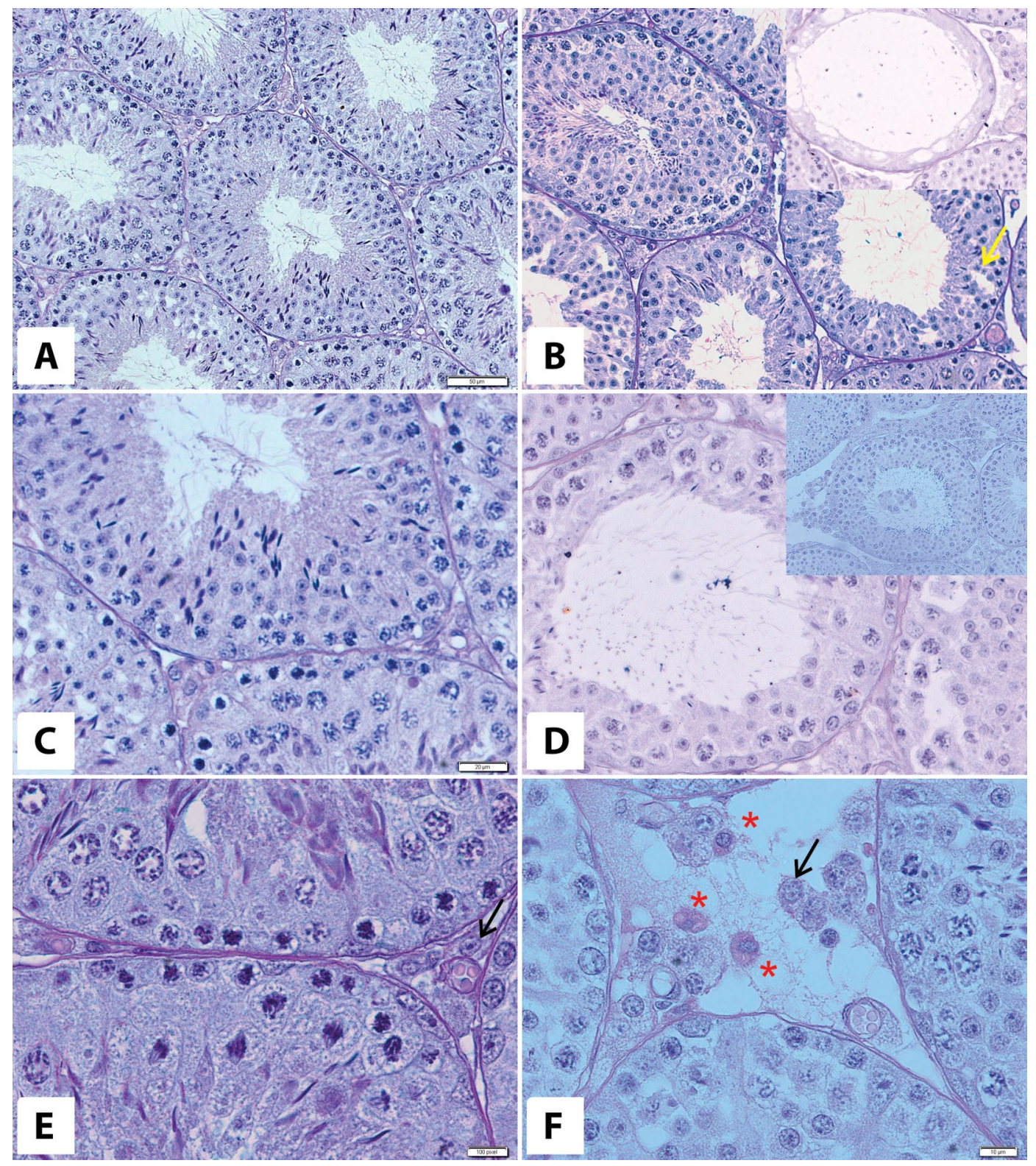

Figure 2. Morphology of testes of 12-month-old WT (A, C, E) and bGH mice (B, D, F). Yellow arrow — vacuole, black arrows - Leydig cells, asterisk - lipofuscin-storing cell. Inserts: tubules with missing generations of germ cells (B) and premature sloughed germ cells (D). PAS staining. Magnifications: $\times 20$ (A, B), $\times 40(C, D), \times 60$ (E, F). Only representative microphotographs are presented

In 12-month-old WT animals, the reaction was strongly positive and in bGH mice was weakly positive. The positive reaction was also observed in peritubular myoid cells of 6-month-old WT and bGH mice and 12-month-old WT mice (Figure 3 E-H, Table 1).

\section{Diameter of seminiferous tubules of 6- and 12-month-old bGH vs. control WT mice}

We noted differences in the diameters of seminiferous tubules between bGH and WT mice.
Average and median of the diameter of tubules in 6-month-old bGH mice was statistically significantly greater than in 6-month-old WT animals (Table 2). However, average and median diameter of seminiferous tubules in 12-month-old bGH mice was smaller as compared to WT mice of the same age (Table 2).

Moreover, average and median diameters of the seminiferous tubules of 12-month-old bGH group were smaller as compared to 6 months old bGH mice (Table 2). 

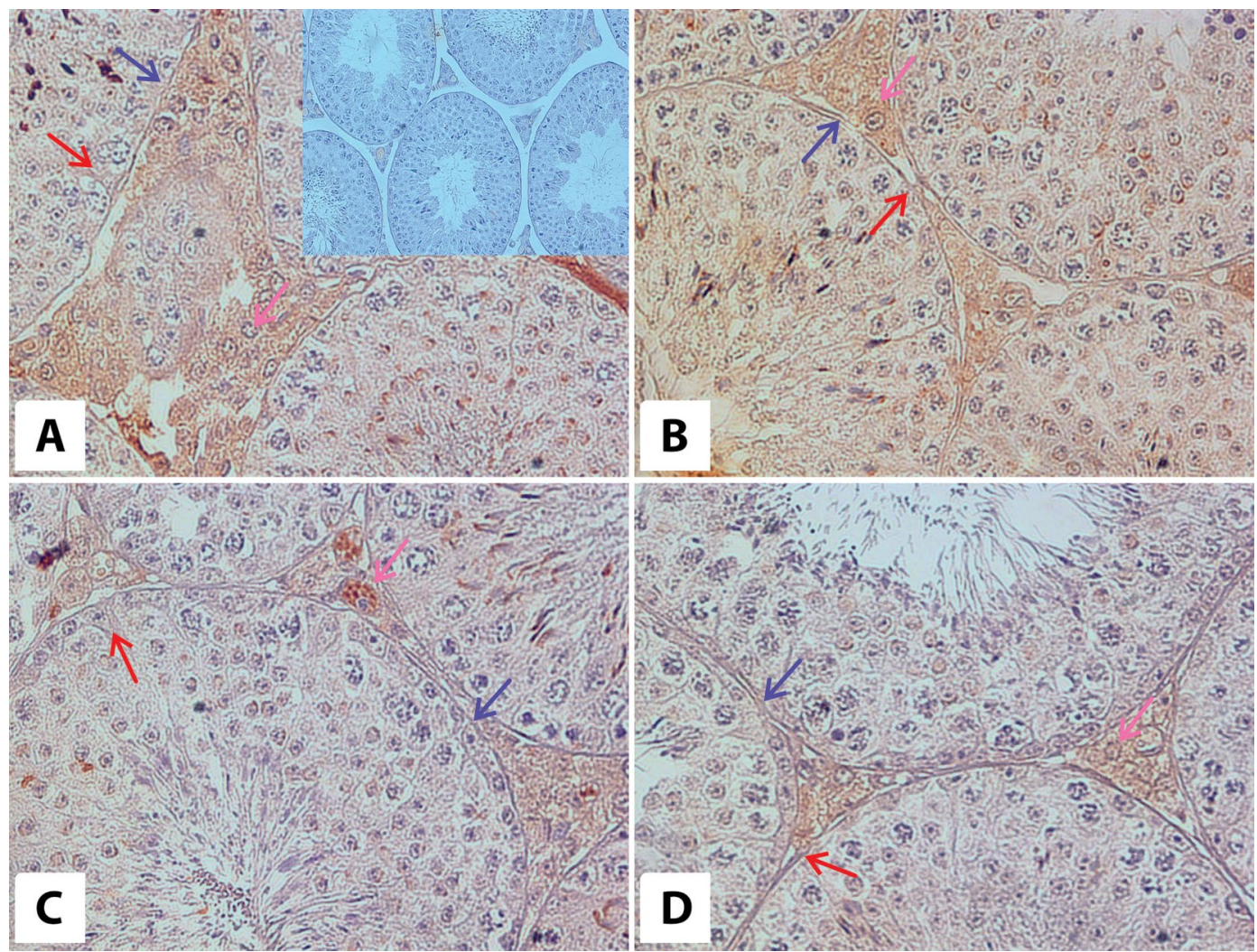

Figure 3. Immunoexpression of androgen receptors in testes of 6-month-old WT (A) and bGH (B) and 12-month-old WT (C) and bGH (D) mice. Brown arrows - Sertoli cells, magenta arrows - Leydig cells, blue arrows - peritubular cells. Magnification: $\times 40$. Upper insert on panel A - negative control $(\times 20)$

Table 1. Intensity of immunostaining of AR and LHR in the testes of WT and bGH mice in both age groups

\begin{tabular}{|l|c|c|c|c|c|c|c|c|}
\hline \multirow{2}{*}{ Cell type } & \multicolumn{4}{|c|}{ AR } & \multicolumn{4}{c|}{ LHR } \\
\cline { 2 - 9 } & 6mo WT & 6mo bGH & 12mo WT & 12mo bGH & 6mo WT & 6mo bGH & 12mo WT & 12mo bGH \\
\hline Leydig cells & ++ & ++ & +++ & ++ & +++ & +++ & +++ & + \\
\hline Sertoli cells & ++ & ++ & + & + & - & - & - & - \\
\hline Peritubular & + & + & + & + & + & + & + & $-/+$ \\
\hline Germ cells & +++ & ++ & + & + & - & - & - & - \\
\hline
\end{tabular}

Intensity of immunoexpression scored as negative $(-)$, weakly positive $(+)$, moderately positive $(++)$, strongly positive $(+++)$

Table 2. Diameters of seminiferous tubules in WT and bGH mice of different ages

\begin{tabular}{|l|c|c|c|}
\hline Group & $\begin{array}{c}\text { Average } \\
{[\mu \mathbf{m}]}\end{array}$ & $\begin{array}{c}\text { SD } \\
{[\mu \mathbf{m}]}\end{array}$ & $\begin{array}{c}\text { Median } \\
{[\mu \mathbf{m}]}\end{array}$ \\
\hline $6 \mathrm{mo} \mathrm{WT}$ & $185.91^{*}$ & 13.79 & 183.76 \\
\hline $6 \mathrm{mo} \mathrm{bGH}$ & $200.08^{*}$ & 13.79 & 198.17 \\
\hline $12 \mathrm{mo} W T$ & $195.58^{* *}$ & 14.82 & 194.33 \\
\hline $12 \mathrm{mo} \mathrm{bGH}$ & $180.14^{* *}$ & 11.76 & 178.36 \\
\hline
\end{tabular}

Statistically significant difference, ${ }^{*} \mathrm{p}<0.001$ and ${ }^{* *} \mathrm{p}<0.0001$ (n $=8$ in each group)

\section{Discussion}

Mice overexpressing bGH have increased adult body size, reduced life span and reproductive abnormalities found both in males and females [10]. Somatotropin is important factor of testicular growth and maturation. Normal level of GH promotes maturation and generation of proper number of mature Leydig cells, and GHR is present in all stages of development of Lc $[14,18]$. GH is also involved in assuring a proper level of spermatogenesis, sperm morphology and 


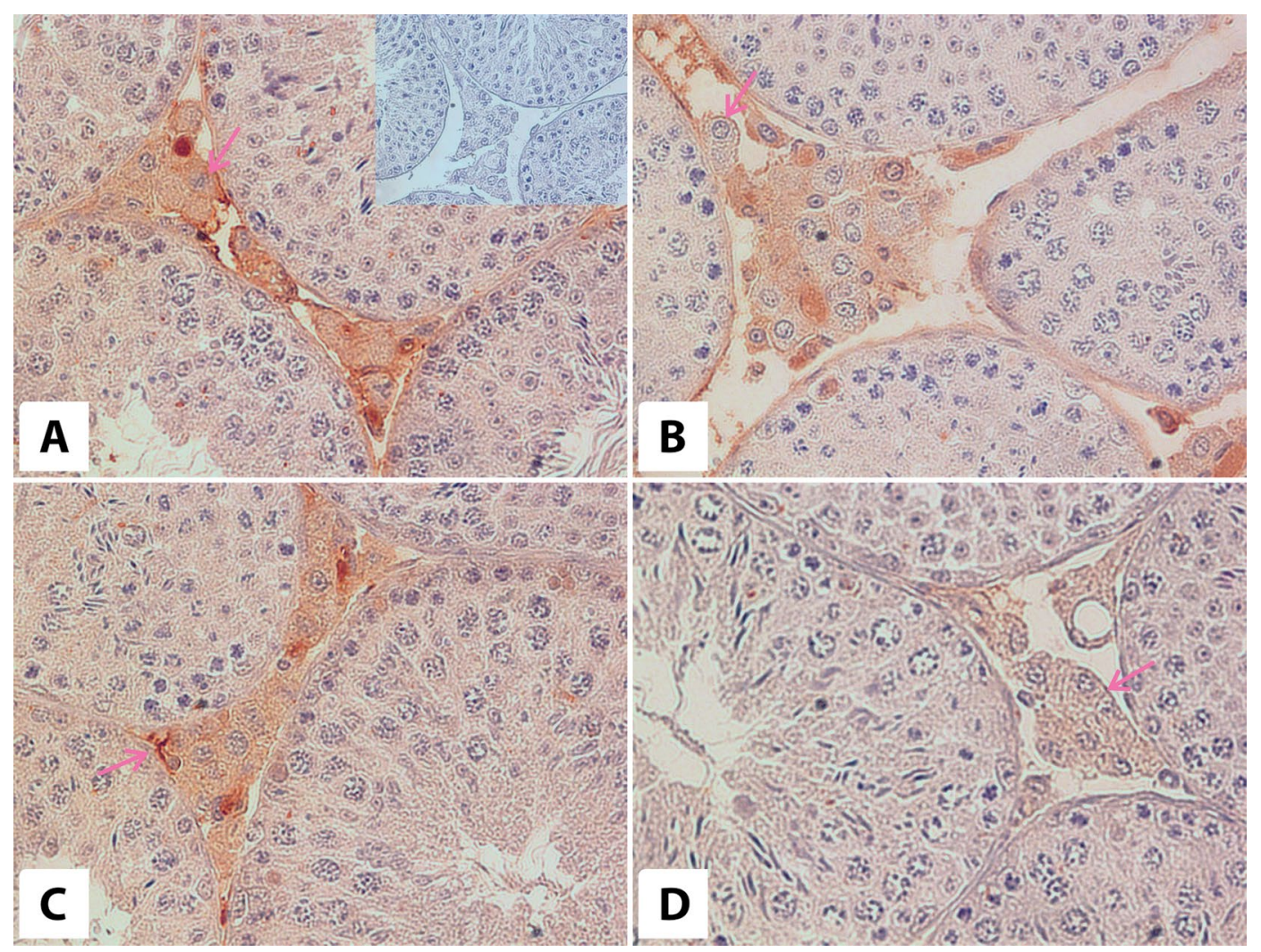

Figure 4. Immunoexpression of LH receptors in testes of 6-month-old WT (A) and bGH (B) and 12-month-old WT (C) and bGH (D) mice. Magenta arrows - Leydig cells. Magnification: $\times 40$. Insert on panel A - negative control $(\times 40)$

motility. Those actions are mediated by local production of IGF-1 in testicular cells: Leydig cells, Sertoli cells (Sc) and peritubular cells $[11,19]$. Somatotropin and IGF-1 are involved in testosterone production (primary by regulating the responsiveness to $\mathrm{LH}$ ), in differentiation of type A spermatogonia and also exert anti-apoptotic effect on testicular cells $[6,18,19,20]$.

We analyzed seminiferous tubules in 6- and 12-month-old PEPCK/bGH transgenic mice compared to their normal WT littermates. In 6-monthold bGH mice, we noted normal roper structure of seminiferous epithelium, with all generations of germ cells. However, we also observed some tubules without germ cells, "Sertoli Cells only" tubules. Anniballo et al. described "Sertoli Cells only" tubules as structures lacking germ cells, but with Sertoli cells attached to the basal membrane of tubules exhibiting a well-shaped nucleus [21]. We also revealed presence of some tubules with arrested spermatogenesis and containing small vacuoles in a basal part of seminiferous epithelium. Those changes were absent in normal mice of similar age. Additionally, in 12-month-old bGH mice we found increased number of cells storing lipofuscin granules (there were single cells only in 6-month-old bGH mice).
Morphological abnormalities observed in 12-month-old bGH animals as compared to 6-monthold bGH mice are described in literature assigns of testicular aging (reviewed in [22]). However, some of these phenomena were also described in conditions of altered hormonal balance. Kondarewicz and coworkers described in rat testes presence of multinucleated giant cells, premature sloughed germ cells, vacuoles and high number of lipofuscin-storing cells as the result of reduced estradiol level due to the inhibition of aromatase P450 by letrozole [23]. Estrogen levels are probably not decreased in mice overexpressing $\mathrm{GH}$, as GH and IGF-1 stimulate aromatase activity in vitro and in vivo [24, 25]. Moreover, GH treatment leads to increased level of plasma estrogens and increased estrogen/testosterone ratio (E/T ratio), with unchanged level of testosterone in young men [25]. Additionally, in mice with dysfunctional GH receptor (GHRKO) characterized by decreased action of GH and undetectable level of plasma IGF-1, plasma testosterone and testicular level of IGF-1 are decreased in comparison to normal mice of the same age [26]. Further studies could explain if the observed changes in testes of bGH mice are due to high level of estrogens during the development and maturation. Early 
exposure to estrogenic compounds was reported to produce an increase of tubular diameter in testes [27]. Additionally, Strauss et al. described hypertrophy and cholesterol accumulation in Leydig cells of mice overexpressing aromatase $\mathrm{P} 450\left(\mathrm{AROM}^{+}\right.$mice) [28]. Hypertrophy and well developed lipid droplets in cytoplasm of Leydig cells were observed also in the bGH transgenic mice in the present experiment. We would like to speculate, that the observed changes may have resulted from an increase in estrogen level due to the overexpression of GH and high level of IGF-1.

We also observed increased amount of cells storing lipofuscin granules. In healthy normal male mice, the age of 12 months represents approximately half of their lifespan. The presence of the lipofuscin granules in Leydig cells has been described as a symptom of testicular aging [22]. Some authors describe this phenomenon also in states of decreased estrogen level [23]. As mentioned above, bGH mice are short-lived, and at 12 months they are approaching the end of their normal lifespan [7] and GH can increase estrogen levels [25]. Therefore, we assume that increased amount of lipofuscin-storing cells is a sign of aging in bGH mice. Another phenomenon present in 12-month-old bGH mice is premature sloughing of germ cells. It was described by Pilutin et al. for decreased estrogen level and by Tanemura and coworkers in aging BDF1 mice [29, 30]. In BDF1 mice, the symptoms of aging (vacuoles in seminiferous epithelium, sloughed germ cells) appeared at 18 months of age [30]. The presence of these symptoms in our 12-month-old bGH mice may thus indicate some features of premature aging.

It has been reported that bGH mice have larger testes, and that absolute weight of the testes was greater in GH-transgenic males and proportional to body weight [9]. However, it was not clear if greater mass of the testes is due to an increase in interstitial tissue or size of seminiferous tubules. In our current study, we noted tubules with larger diameters in bGH mice (in both groups: 6- and 12-month-old mice) as compared to their normal WT littermates, which is in agreement with the $\mathrm{GH}$ effects on the testis. GH plays an important role in testicular growth, development and testicular function, including steroidogenesis and gametogenesis [11]. We also observed that the diameter of tubules decreased with age in bGH animals, which supports previous findings in aging mice [31] and aging Syrian hamsters [32].

In our present study the localization of AR was confirmed in Sertoli cells, Leydig cells and peritubular cells of testes from all groups of experimental animals, which is in agreement with other studies in laboratory rodents [29]. We also observed reactivity to AR in spermatids. This is not a typical localization of this protein, however, there are studies showing presence of AR in germ cells in human and rodent testes [29, 33]. Cytoplasmic localization of AR found in Sertoli and Leydig cells is consistent with steroid hormones action. Unliganded steroid receptors are present in the cytoplasm, while ligand-receptor complexes are found in the nucleus [34, 35]. The modest decrease in the expression of $\mathrm{AR}$ in testes of bGH mice may be the result of changed $\mathrm{E} / \mathrm{T}$ ratio due to chronic GH overexpression and decreased level of testosterone in bGH males which were previously reported [36].

The immunolocalization of LHR was confirmed for Leydig cells in all experimental groups. The decreased level of immunoexpression of LHR in older (12-month-old) bGH transgenic animals suggests accelerated aging of Leydig cells. Chen et al. describe five stages of development of Leydig cells in rodent testes [37]. The stages of development of these cells are characterized by morphological (abundance of smooth ER) and physiological features (production and metabolism of testosterone), and presence of AR and LHR [37]. According to this description the main alternations during aging of Leydig cells are: i) reduced level of T synthesis, ii) presence of LHR: high in adult $v s$ moderate in aging Leydig cells [37]. We found that in 12-month-old bGH mice the population of Leydig cells is composed of adult and aging cells. In our study we also detected immunolocalization of LHR in cells in peritubular region. The presence of LHR in peritubular cells was not previously reported in mammals. On the other hand, Ge et al. described rat progenitor Leydig cells as spindle-like cells found in peritubular layer which expressed LHR [38]. The progenitor cells are lost with age and we also observed loss of peritubular immunoexpression of LHR in 12-month-oldbGH and control mice.

In conclusion, our morphological study documenting apparently normal spermatogenesis in 12-month-old bGH mice agree with previous reports that bGH male mice are fertile [9]. We showed that structures of bGH testes responsible for sperm production, including Leydig cells and seminiferous epithelium, are essentially normally developed, although the tubules are wider. Moreover, in 12-month-old bGH mice some changes of the seminiferous epithelium and Leydig cells suggest disturbed hormonal balance and symptoms of aging.

\section{References}

1. Berryman DE, List EO, Coschigano KT et al. Comparing adiposity profiles in three mouse models with altered $\mathrm{GH}$ signaling. Growth Horm IGF Res. 2004;14:309-318. doi: 10.1016/j.ghir.2004.02.005. 
2. Iida K, Del Rincon JP, Kim DS et al. Tissue-specific regulation of growth hormone receptor and insulin like growth factor-I gene expression in the pituitary and liver of GH deficient (lit/lit) mice and transgenic mice that overexpress bovine GH (bGH) or a bGH antagonist. Endocrinology. 2004;145:1564-1570. doi: 10.1210/en.2003-1486.

3. Brown-Borg HM. Hormonal control of aging in rodents: the somatotropic axis. Mol Cell Endocrinol. 2009;299:64-71. doi: 10.1016/j.mce.2008.07.001.

4. Masternak MM, Panici JA, Bonkowski MS et al. Insulin sensitivity as a key mediator of growth hormone actions on longevity. J Gerontol. 2009;64A:516-521. doi: 10.1093/ Gerona/glp024.

5. Palmer AJ, Chung MY, List EO et al. Age-related changes in body composition of bovine growth hormone transgenic mice. Endocrinology. 2009;150:1353-1360. doi: 10.1210/ en.2008-1199.

6. Chandrashekar V, Bartke A, Awoniyi CA et al. Testicular endocrine function in $\mathrm{GH}$ receptor gene disrupted mice. Endocrinology. 2001;142:3443-3450. PMID: 11459789.

7. Bartke A, Chandrashekar V, Bailey B, Zaczek D, Turyn D. Consequences of growth hormone $(\mathrm{GH})$ overexpression and GH resistance. Neuropeptides. 2002;36:201-208. doi: 10.1054/ npep.20020889.

8. Bartke A. Growth hormone, insulin and aging: the benefits of endocrine defects. Exp Gerontol. 2010;46:108-111. doi: 10.1016/j.exger.2010.08.020.

9. Bartke A, Naar EM, Johnson L et al. Effects of expression of human or bovine growth hormone genes on sperm production and male reproductive performance in four lines of transgenic mice.J Reprod Fert. 1992;95:109-118. doi: $\underline{10.1530 /}$ jrf.0.0950109.

10. Bartke A, Cecim M, Tang K et al. Neuroendocrine and reproductive consequences of overexpression of growth hormone in transgenic mice. Proc Soc Exp Biol Med.1994;206:345-359. doi: $10.3181 / 00379727-206-43771$.

11. Hull KL, Harvey S. Growth hormone: a reproductive endocrine-paracrine regulator? Rev Reprod. 2000;5:175-182. doi: 10.1530/revreprod/5.3.175.

12. Childs GV. Growth hormone cells as co-gonadotropes: partners in the regulation of the reproductive system. TEM. 2000;11:168-175. doi: 10.1016/S1043-2760(00)00252-6.

13. Spiteri-Grech J, Nieschlag E. The role of growth hormone and insulin-like growth factor $I$ in the regulation of male reproductive function. Horm Res. 1992;1:22-27. doi: $\underline{10.1159 / 000182566}$

14. Kazaki M, Morris P. Growth hormone regulates steroidogenic acute regulatory protein expression and steroidogenesis in Leydig cell progenitors. Endocrinology. 1999;140:1681-1686. doi: $10.1210 /$ endo.140.4.6661.

15. Piotrowska K, Borkowska SJ, Wiszniewska B et al. The effect of low and high plasma levels of insulin-like growth factor-1 (IGF-1) on the morphology of major organs-studies of Laron dwarf and bovine growth hormone transgenic (bGHTg) mice. Histol Histopathol. 2013;28:1325-1336. doi: $\underline{10.14670 /}$ HH-28.1325.

16. McGrane MM, De Vente J, Yun J et al. Tissue-specific expression and dietary regulation of a chimeric phosphoenolpyruvate carboxykinase/bovine growth hormone gene in transgenic mice. J Biol Chem. 1988;263:11443-11451. PMID: 2841327.

17. Neves ES, Chiarini-Garcia H, Franca LR. Comparative testis morphometry and seminiferous epithelium cycle length in donkey and mules. Biol Reprod. 2002;67:247-255. doi: 10.1095/ biolreprod.67.1.247.

18. Wang G, Hardy MP. Development of Leydig cells in the Insulin-like Growth Factor-I (IGF-I) knockout mouse: effects of IGF-I replacement and gonadotropin stimulation. Biol Reprod. 2004;70:632-639. doi: 10.1095/biolreprod.103.022590.

19. Roser JF. Regulation of testicular function in the stallion: An intricate network of endocrine, paracrine and autocrine systems. Anim Reprod Sci. 2008;107:179-196. doi: 10.1016/j. anireprosci.200805.004

20. Yoon MJ, Roser JF. Insulin-like Growth Factor- I (IGF-I) protects cultured equine Leydig cells from undergoing apoptosis. Animal Reprod Sci. 2010;122:353-358. doi: 10.1016/j. anireprosci.2010.10.001.

21. Anniballo R, Brehm R, Steger K. Recognising the Sertoli-cell-only (SCO) syndrome: a case study. Andrologia. 2011;43:78-83. doi: 10.1111/j.1439-0272.2009.01030.x.

22. Hermann M, Untergasser G, Rumpold H, Berger P. Aging of the male reproductive system. Exp Gerontol. 2000;35:1267-1279. doi: 10.1016/S0531-5565(00)00159-5.

23. Kondarewicz A, Kolasa A, Zawislak B et al. Testis morphology in rat chronically treated with letrozole, an aromatase inhibitor. Folia Histochem Cytobiol. 2011;49:677-684. doi: 10.5303/FHC.2011.0091.

24. Zhang B, Shozu M, Okada M et al. Insulin-like growth factor I enhances the expression of aromatase $\mathrm{P} 450$ by inhibiting autophagy. Endocrinology. 2010;151:4949-4958. doi: 10.1210/ en.2010-0294.

25. Andreassen M, Frystryk J, Faber J et al. Growth hormone (GH) activity is associated with increased serum oestradiol and reduced Anti-Müllerian Hormone in healthy male volunteers treated with GH and GH antagonists. Andrology. 2013;1:595-601. doi: 10.1111/j.2047-2927.2013.00096.x.

26. Chandrashekar V, Dawson CR, Martin ER et al. Age-related alternations in pituitary and testicular functions in long-lived growth hormone receptor gene-disrupted mice. Endocrinology. 2007;148:6019-6025. doi: 10.1210/en.2007-0837.

27. Brown NM, Lindley SL, Witte DP et al. Impact of perinatal exposure to equol enantiomers on reproductive development in rodents. Reprod Toxicol. 2011;32:33-42. doi: 10.1016/j. reprotox.2011.05.008.

28. Strauss L, Kallio J, Desai N et al. Increased exposure to estrogens disturbs maturation, steroidogenesis, and cholesterol homeostasis via estrogen receptor alpha in adult mouse Leydig cells. Endocrinology. 2009;150:2865-2872. doi: 10.1210/en.2008-1311.

29. Pilutin A, Misiakiewicz-Hass K, Kolasa A et al. The immunoexpression of androgen receptor, estrogen receptors $\alpha$ and $\beta$, vanilloid type 1 receptor and cytochrome p 450 aromatase in rats testis chronically treated with letrozole, an aromatase inhibitor. Folia Histochem Cytobiol. 2014;52:206-217. doi: 10.5603/FHC.2014.0024.

30. Tanemura K, Kurohmaru M, Kuramoto K, Hayashi Y. Age -related morphological changes in the testis of the BDF1 mouse. J Vet Med Sci. 1993;55:703-710. PMID: 8286519.

31. Mehraein F, Negahdar F. Morphometric evaluation of seminiferous tubules in ages mice testes after melatonin administration. Cell J. 2011;13:1-4. PMID: 23671820.

32. Morales E, Horn R, Pastor LM et al. Involution of seminiferous tubules in aged hamsters: an ultrastructural, immunohistochemical and quantitative morphological study. Histol Histopathol. 2004;19:445-455. PMID: 15024705.

33. Kimura N, Mizokami A, Onuma $\mathrm{T}$ et al. Immunohistochemical Localization of androgen receptor with polyclonal 
antibody in paraffin-embedded human tissues. J Histochem Cytochem. 1993;41:671-678. doi: 10.1177/41.5.8468448.

34. DeFranco DB. Regulation of steroid receptor subcellular trafficking. Cell Biochem Biophys. 1999;30:1-24. doi: 10.1007/ BF02737882.

35. Kawata M. Subcellular steroid nuclear receptor dynamics. Arch Histol Cytol. 2001;64:353-368. doi: 10.1679/aohc.64.353.

36. Rocha JS, Bonkowski MS, de França LR et al. Effects of mild calorie restriction on reproduction, plasma parameters and hepatic gene expression in mice with altered GH/IGF-I axis. Mech Aging Dev. 2007;128:317-331. doi: 10.1016/j.mad.2007.02.001.
37. Chen H, Ge RS, Zirkin BR. Leydig cells: from stem cells to aging. Mol Cell Endocrinol. 2009;306:9-16. doi: 10.1016/j. mce.2009.01.023.

38. Ge RS, Dong Q, Sottas CM et al. In search of rat stem Leydig cells: Identification, isolation, and lineage-specyfic development. Proc Natl Acad Sci USA. 2006;103:2719-2724. doi: 10.1073/pnas.0507692103.

39. Yang CW, Striker LJ, Pesce C et al. Gromerulosclerosis and body growth are mediated by different portions of bovine growth hormone. Studies in transgenic mice. Lab Invest. 1993;68:62-71. PMID: 8423678.

Submitted: 22 January, 2015

Accepted after reviews: 7 September, 2015

Available as AoP: 8 September, 2015 